\title{
Ageing embodiment and the search for social change
}

\author{
By EMmanuelle Tulle ${ }^{1}$ \& CLARY KREKula ${ }^{2}$
}

When we issued our call for contributions to this special section, we intended to showcase the potential for the theoretical and conceptual enrichment that the turn to the body in ageing studies has given rise to. The proliferation of writings in this area is to be welcome, especially if it is going to encourage critical evaluations of the conditions in which ageing is imagined, "practised" and regulated. The growing interest in ageing bodies has taken place against a backdrop in which knowledge about old age was being questioned. A particular target of this process of questioning was scientific expertise, and the urge to extract of set of objective principles constituting ageing as a universal and therefore homogeneous condition, from which little deviation could be envisaged (Katz 1996; Vincent 2006).

Questioning the scienticisation of ageing did not augur an abandonment of the bodily dimension of ageing. What it meant was that the biological was no longer the unique reference point in the truth of ageing and old age. The social dimension (broadly speaking) of ageing and old age became salient and freed scholarship from intellectual impoverishment. The turn to the body in ageing has had four moments: (1) the identification and examination of the discursive conditions in which the truth of ageing

\footnotetext{
${ }^{1}$ Emmanuelle Tulle, Department of Social Sciences, Media and Journalism, Glasgow School for Business and Society, Glasgow Caledonian University, Glasgow, UK

${ }^{2}$ Clary Krekula, Department of Social and Psychological Studies, Karlstad University, Karlstad, Sweden
} 
International Journal of Ageing and Later Life

was constituted (see for example Katz 1996); (2) a focus on visual and fictional representations of ageing, including ageing bodies and how these might inform or be informed by more general public and political anxieties about ageing as a social problem (see for example Faircloth 2003, Featherstone \& Wernick 1995; Gilleard \& Higgs 2001, 2013); (3) the performance of ageing, that is, how people position themselves as old or otherwise (see for example Woodward 1999); and (4) the materiality of ageing and how it is experienced at a more intimate (phenomenological) level (see for example Laz 2003).

Bodies became social - not inert shells containing our souls - but endowed with meaning, contingency and perhaps intention. Of course bodies are also governed by biological processes which we engage with throughout our lives. When we experience pain, illness, tiredness and impairments, we have to contend with our carnality. As men and women we also engage with our bodies in distinctive ways. The key message here is that the relationship we have with our bodies takes place over time, in accordance with meanings, values, norms - which are social (Crossley 2001). We do not invent them - we often reproduce them or others reproduce them through us.

Older bodies present particular challenges. The carnality of growing older has to be attended to and often this engenders the re-negotiation of identity. For our bodies, as the dynamic receptacles of our existence, are tied up with our deepest sense of self. This is my body, I recognise this body as mine. Even if I don't particularly like my body, I still experience it in intimate ways and this is a reminder of my existence and of myself as I have developed a very long relationship with it. Over time I may grow to fear what happens to it and seek ways to reassert myself by negotiating a changed relationship to my body. This renegotiation might also be prompted by others for whom my body represents something negative or undesirable. This process of renegotiation is highly social.

Asserting the sociality of bodies, as objects of knowledge and systematic study, as a target of representations and source of meaning, as our own medium for asserting who we are or would like to be, as something we live with and with which we develop a close relationship, is what we refer to as embodiment.

Ageing embodiment, whilst a rich source of scholarship, has rarely been attributed positive meaning. The discursive space in which it is captured 
Ageing embodiment and social change

continues to throw up a largely negative iconography steeped in a language of loss, erosion, lack, decline, a medicalised reality of decrements. There is a strong connection between the privileging of this semantic space and the cultural position of the old.

The demographic transformations which have led to what is commonly referred to as population ageing and have made the old much more visible - a triumph of longevity - have also exposed the widespread dissemination of social and cultural practices which denigrate the old and inhibit the search for acceptable alternatives.

Our call for contributions to this special section of IJAL was designed to move scholarship beyond description and critique, and to find in experiences of ageing embodiment the potential for challenging the dominant discourse of ageing and old age, documenting processes which do not reproduce the language of age but bring comfort to social actors, transform meanings, make difference visible without normalising enfeebling tendencies nor minimising the carnality of old age, restore capital in sum, by proposing conceptualisations which have the potential to free us from restrictive norms, unlocking the creativity of ageing social actors, decentering practices of power and restoring value to ageing. To this end we are presenting in this issue two articles which grappled with the potential for significant social change invested in ways of conceptualising and theorising ageing embodiment which foreground gender, albeit from two different starting points.

Sandberg's article uses feminist theory and in particular the feminist corpomaterialist concept of "affirmative difference" (Grosz 1994) to provide an alternative conceptualisation of ageing embodiment. This concept enables her to detect how men and women find pleasure in their changed bodies, in the process transgressing strict binary conceptions of gendered embodiment and pleasure. It is as if bodily ageing, far from restricting experience, becomes an opportunity not only to discover a new language of old age but also to redraw carnality. Following Deleuze and Irigaray, Sandberg posits that ageing bodies can be the site for the proliferation and production of different and unexpected meanings.

The latter is what Gravagne captures in her article, also drawing on the work of Grosz and Deleuze to critique the straightjacket in which dominant conceptions of time as strictly linear chronology encase and 
International Journal of Ageing and Later Life

thus weaken our imaginings of later life. She engages in an analysis of a film - Strangers in Good Company - in which seven older women, played by non-professional actresses, who become stranded in a remote part of Quebec when their bus breaks down, have to find ways of surviving without depending on men or younger people. The women develop interdependencies based on the discovery of skills and resourcefulness which belie chronological age. Gravagne argues that art, and film in particular, can be used to blur the boundary between the virtual images of fiction and reality, enabling "magic" to be discerned in the experiences and lives of these women, encouraging the viewer to imagine ageing lives in less predictable ways.

These articles provide examples of how eclectic theoretical approaches open up new perspectives on ageing embodiment. They, thus, reflect a part of contemporary research within the field. While working on this thematic section, a number of reviewers contributed with constructive input. We would like to thank them for their contribution.

\section{References}

Crossley, N. (2001). The Social Body - Habit, Identity and Desire. London: Sage. Faircloth, C. A. (ed.). (2003). Aging Bodies: Images and Everyday Experience. Oxford: Altamira Press.

Featherstone, M. \& Wernick, A. (eds.). (1995). Images of Ageing. Cultural Representations of Later Life. London: Routledge.

Gilleard, C. \& Higgs, P. (2001). Cultures of Aging: Self, Citizen, and the Body. London: Routledge.

Gilleard, C. \& Higgs, P. (2013). Ageing, Corporeality and Embodiment. London: Anthem press.

Grosz, E. (1994). Volatile Bodies: Towards a Corporeal Feminism. Indianapolis, IN: Indiana University Press.

Katz, S. (1996). Disciplining Old Age. The Formation of Gerontological Knowledge. Charlottesville, VA: University of Virginia Press.

Laz, C. (2003). Age embodied. Journal of Aging Studies 17: 503-519.

Vincent, J. A. (2006). Ageing contested: Anti-ageing science and the cultural construction of old age. Sociology 4(4): 681-698.

Woodward, K. (ed.). (1999). Figuring Age: Women, Bodies, Generations. Bloomington, IN: Indiana University Press. 